\title{
RUANG SEMI HASIL KALI DALAM PADA RUANG BERNORM KOMPLEKS
}

\author{
NADYA PUSPITA SARI, HARIPAMYU, SHELVI EKARIANI \\ Program Studi S1 Matematika, \\ Fakultas Matematika dan Ilmu Pengetahuan Alam, Universitas Andalas, \\ Kampus UNAND Limau Manis Padang, Indonesia. \\ email : saripuspitanadya@gmail.com
}

Diterima 22 Juni 2019 Direvisi 6 Juli 2019 Dipublikasikan 4 Agustus 2019

\begin{abstract}
Abstrak. Suatu ruang hasil kali dalam adalah suatu ruang bernorm. Namun secara umum, suatu ruang bernorm bukan ruang hasil kali dalam. Teori pada ruang hasil kali dalam merupakan teori yang paling banyak dikembangkan. Namun teori tersebut tidak berlaku secara umum pada ruang bernorm. Agar teori tersebut juga berlaku pada ruang bernorm, ruang hasil kali dalam digeneralisasi menjadi ruang semi hasil kali dalam, sehingga suatu ruang bernorm dapat dibentuk menjadi ruang semi hasil kali dalam.
\end{abstract}

Kata Kunci: Ruang Bernorm, Ruang Semi Hasil Kali dalam

\section{Pendahuluan}

Suatu ruang hasil kali dalam merupakan ruang bernorm, dengan norm yang diinduksi dari hasil kali dalamnya. Namun secara umum, ruang bernorm bukanlah ruang hasil kali dalam. Teori pada ruang hasil kali dalam merupakan teori yang paling banyak dikembangkan. Namun teori tersebut tidak berlaku secara umum pada ruang bernorm. Agar teori tersebut juga berlaku pada ruang bernorm, pada tahun 1961, Lumer [6] menggeneralisasi ruang hasil kali dalam yang disebut sebagai ruang semi hasil kali dalam Lumer. Pada tahun 1967 Giles mengembangkan konsep ruang semi hasil kali dalam Lumer dengan menambahkan sifat homogenitas pada definisi ruang semi hasil kali dalam Lumer. Hasil pengembangan ini disebut ruang semi hasil kali dalam Lumer-Giles atau disingkat sebagai ruang semi hasil kali dalam. Pada penelitian ini akan dikaji definisi ruang semi hasil kali dalam, eksistensi semi hasil kali dalam pada ruang bernorm beserta contoh ruang semi hasi kali dalam.

\section{Landasan Teori}

\subsection{Operator Linear}

Definisi 2.1. [7] Misalkan $X$ dan $Y$ suatu ruang vektor atas lapangan $K$. Maka suatu fungsi $T: X \longrightarrow Y$ disebut operator linear jika dan hanya jika untuk setiap $x, y \in X$ dan $\alpha, \beta$ skalar, 
Nadya Puspita Sari dkk.

$$
T(\alpha x+\beta y)=\alpha T(x)+\beta T(y)
$$

Selanjutnya penulisan $T(x)$ disingkat menjadi $T x$, penyingkatan ini merupakan standar penulisan pada analisis fungsional.

Definisi 2.2. [5] Misalkan $\left(X,\|\cdot\|_{X}\right)$ dan $\left(Y,\|\cdot\|_{Y}\right)$ suatu ruang bernorm atas lapangan $K$. Suatu operator linear $T: \mathfrak{D}(T) \longrightarrow Y$, dimana $\mathfrak{D}(T) \subset X$. Operator $T$ dikatakan terbatas jika terdapat suatu bilangan riil c sedemikian hingga untuk setiap $x \in \mathfrak{D}(T)$,

$$
\|T x\|_{Y} \leqq c\|x\|_{X}
$$

Definisi 2.3. [5] Misalkan $\left(X,\|\cdot\|_{X}\right)$ dan $\left(Y,\|\cdot\|_{Y}\right)$ suatu ruang bernorm atas lapangan $K$. Suatu operator $T: \mathfrak{D}(T) \longrightarrow Y$, dimana $\mathfrak{D}(T) \subset X$. Operator $T$ dikatakan kontinu pada suatu titik $x_{0} \in X$ jika untuk setiap $\epsilon>0$ terdapat $\delta>0$ sedemikian hingga $\left\|T x-T x_{0}\right\|_{Y}<\epsilon$, untuk setiap $x \in \mathfrak{D}(T)$ yang memenuhi $\left\|x-x_{0}\right\|_{X}<\delta$. T dikatakan kontinu jika $T$ kontinu di setiap $x \in \mathfrak{D}(T)$.

Teorema 2.4. [5] Misalkan $T: \mathfrak{D}(T) \longrightarrow Y$ suatu operator linear, dimana $\mathfrak{D}(T) \subset$ $X,\left(X,\|\cdot\|_{X}\right)$ dan $\left(Y,\|.\|_{Y}\right)$ suatu ruang bernorm atas lapangan $K$, maka

(1) T kontinu jika dan hanya jika $T$ terbatas.

(2) Jika $T$ kontinu pada suatu titik $x_{0} \in \mathfrak{D}(T)$, maka $T$ kontinu.

\subsection{Fungsional Linear}

Definisi 2.5. [7] Misalkan $X$ suatu ruang vektor atas lapangan skalar $K . f$ adalah suatu fungsional linear pada $X$ jika $f: X \longrightarrow K$ merupakan suatu operator linear.

Definisi 2.6. [5] Misalkan $(X,\|\|$.$) suatu ruang bernorm atas lapangan K$. Suatu fungsional linear $f: \mathfrak{D}(f) \longrightarrow K$, dimana $\mathfrak{D}(f) \subset X$. Fungsional $f$ dikatakan terbatas jika terdapat suatu bilangan riil c sedemikian hingga untuk setiap $x \in \mathfrak{D}(f)$

$$
|f(x)| \leqq c\|x\|
$$

Definisi 2.7. [5] Misalkan (X,\|.\|) suatu ruang bernorm atas lapangan $K$. Suatu fungsional $f: \mathfrak{D}(f) \longrightarrow K$, dimana $\mathfrak{D}(f) \subset X$. Fungsional $f$ dikatakan kontinu pada suatu titik $x_{0} \in X$ jika untuk setiap $\epsilon>0$ terdapat $\delta>0$ sedemikian hingga $\left\|f(x)-f\left(x_{0}\right)\right\|<\epsilon$, untuk setiap $x \in \mathfrak{D}(f)$ yang memenuhi $\left\|x-x_{0}\right\|<\delta$. $f$ dikatakan kontinu jika $f$ kontinu di setiap $x \in \mathfrak{D}(f)$.

Teorema 2.8. [5] Misalkan $f: \mathfrak{D}(f) \longrightarrow K$ suatu fungsional linear, dimana $\mathfrak{D}(f) \subset X$ dan $(X,\|\cdot\|)$ suatu ruang bernorm atas lapangan $K$, maka

(1) $f$ kontinu jika dan hanya jika $f$ terbatas.

(2) Jika $f$ kontinu pada suatu titik $x_{0} \in \mathfrak{D}(f)$, maka $f$ kontinu. 


\subsection{Normalized Duality Mapping}

$X^{*}$ dinotasikan sebagai ruang dual pada suatu ruang bernorm $(X,\|\|$.$) atas lapan-$ gan $K$ dan $\mathcal{P}\left(X^{*}\right)$ merupakan himpunan kuasa dari $X^{*}$.

Definisi 2.9. [2] Misalkan $(X,\|\|$.$) suatu ruang bernorm atas lapangan K$. Suatu pemetaan $\mathrm{\jmath}: X \rightarrow \mathcal{P}\left(X^{*}\right)$ yang didefinisikan sebagai

$$
\jmath(x):=\left\{f \in X^{*}: f(x)=\|x\|^{2} \text { dan }\|f\|=\|x\|\right\}, x \in X
$$

disebut normalized duality mapping dari $X$.

Teorema 2.10. [2] Misalkan $(X,\|\|$.$) suatu ruang bernorm atas lapangan K. Maka:$

(a) Untuk setiap $x \in X$, himpunan $\jmath(x)$ merupakan himpunan bagian tak kosong konveks dari $X^{*}$.

(b) Untuk setiap $x \in X$ dan $\lambda \in K$ berlaku $\jmath(\lambda x)=\bar{\lambda} \jmath(x)$, dimana $\bar{\lambda}$ menotasikan konjugat kompleks dari $X$.

Definisi 2.11. [2] Misalkan J suatu normalized duality mapping pada suatu ruang bernorm $(X,\|\|$.$) atas lapangan K$. Suatu pemetaan $\tilde{\jmath}: X \rightarrow X^{*}$ disebut suatu section pada $\jmath$, jika $\tilde{\jmath}(x) \in \jmath(x)$ untuk setiap $x \in X$.

\subsection{Ruang Hasil Kali Dalam}

Definisi 2.12. [8] Jika diketahui $V$ sebagai ruang vektor atas lapangan $K$. Hasil kali dalam pada $V$ adalah fungsi $\langle.,\rangle:. V \times V \longrightarrow K$ sedemikian hingga untuk setiap $x, y, z \in V$ dan $\alpha, \beta \in K$ memenuhi sifat-sifat berikut:

(1) $\langle x, x\rangle \geq 0$.

(2) $\langle x, x\rangle=0$ jika dan hanya jika $x=0$.

(3) $\langle\alpha x+\beta y, z\rangle=\alpha\langle x, z\rangle+\beta\langle y, x\rangle$.

(4) $\langle x, y\rangle=\overline{\langle y, x\rangle}$.

Pasangan $(V,\langle.,\rangle$.$) disebut ruang hasil kali dalam dimana V$ adalah suatu ruang vektor atas lapangan $K$ dan $\langle.,$.$\rangle adalah suatu hasikali dalam pada V$.

Definisi 2.13. [1] Ruang hasil kali dalam merupakan ruang vektor atas lapangan $K$ yang dilengkapi dengan fungsi hasil kali dalam. Fungsi norm pada suatu ruang hasil kali dalam didefinisikan dengan

$$
\|x\|=\sqrt{\langle x, x\rangle} .
$$

Teorema 2.14. [1] Untuk setiap $x$ dan y pada suatu ruang hasil kali dalam $(V,\langle.,\rangle$. berlaku

$$
|\langle x, y\rangle|^{2} \leq\langle x, x\rangle\langle y, y\rangle
$$

Contoh 2.15. Misalkan $\mathbb{C}^{n}$ suatu ruang vektor kompleks. Suatu fungsi bernilai kompleks $\langle.,\rangle:. \mathbb{C}^{n} \times \mathbb{C}^{n} \longrightarrow \mathbb{C}$ yang didefinisikan sebagai

$$
\langle x, y\rangle=\sum_{i=1}^{n} x_{i} \overline{y_{i}},
$$


dimana $x=\left(x_{1}, x_{2}, \cdots, x_{n}\right), y=\left(y_{1}, y_{2}, \cdots, y_{n}\right) \in \mathbb{C}^{n}$ merupakan suatu hasil kali dalam pada $\mathbb{C}^{n}$.

\section{Pembahasan}

\subsection{Ruang Semi Hasil Kali Dalam}

Definisi 3.1. [2] Suatu semi hasil kali dalam Lumer pada suatu ruang vektor kompleks $V$ adalah sebuah fungsi bernilai kompleks [.,.] : $\times V \rightarrow \mathbb{C}$ sedemikian hingga untuk setiap $x, y, z \in V$ dan $\lambda \in \mathbb{C}$ memenuhi sifat-sifat berikut:

(1) $[x+y, z]=[x, z]+[y, z]$.

(2) $[\lambda x, y]=\lambda[x, y]$.

(3) $[x, x] \geq 0$ untuk setiap $x \in V$ dan $[x, x]=0 \Rightarrow x=0$.

(4) $|[x, y]|^{2} \leq[x, x][y, y]$.

Pasangan $(V,[.,]$.$) disebut ruang semi hasil kali dalam Lumer dimana V$ adalah suatu ruang vektor kompleks dan [.,.] adalah suatu semi hasikali dalam Lumer pada $V$.

Semi hasil kali dalam Lumer pada $V$ selalu menginduksi suatu norm pada $V$ dengan norm yang didefinisikan sebagai $\|x\|=[x, x]^{\frac{1}{2}}$ untuk setiap $x \in V$ dan untuk setiap ruang bernorm kompleks $(V,\|\|$.$) , setidaknya dapat dikontruksikan$ satu semi hasil kali dalam Lumer yang didefinisikan sebagai $[x, x]=\|x\|^{2}$ untuk setiap $x \in V$ [4]. Selanjutnya konsep semi hasil kali dalam Lumer dikembangkan oleh Giles dengan menambahkan sifat homogenitas yaitu :

$$
[x, \lambda y]=\bar{\lambda}[x, y] \text { untuk setiap } x \in V, \lambda \in \mathbb{C} .
$$

Sifat ini ditambahkan pada definisi semi hasil kali dalam Lumer sehingga dapat didefinisikan suatu semi hasil kali dalam Lumer-Giles dengan pendefinisian sebagai berikut.

Definisi 3.2. [2] Suatu semi hasil kali dalam Lumer-Giles atau disingkat dengan semi hasil kali dalam pada suatu ruang vektor kompleks $V$ adalah sebuah fungsi bernilai kompleks [.,.] $: V \times V \rightarrow \mathbb{C}$ sedemikian hingga untuk setiap $x, y, z \in V$ dan $\lambda \in \mathbb{C}$ memenuhi sifat-sifat berikut.

(1) $[x+y, z]=[x, z]+[y, z]$.

(2) $[\lambda x, y]=\lambda[x, y]$ dan $[x, y]=\bar{\lambda}[x, y]$.

(3) $[x, x] \geq 0$ untuk setiap $x \in V$ dan $[x, x]=0 \Rightarrow x=0$.

(4) $|[x, y]|^{2} \leq[x, x][y, y]$.

Pasangan $(V,[.,]$.$) disebut ruang semi hasil kali dalam dimana V$ adalah suatu ruang vektor kompleks dan [.,.] adalah suatu semi hasikali dalam pada $V$.

Teorema 3.3. [2] Misalkan $V$ suatu ruang vektor kompleks dan [.,.] suatu semi hasil kali dalam pada V. Maka

(a) Pemetaan $\|\|:. V \longrightarrow \mathbb{R}$ yang didefinisikan sebagai $\|x\|=[x, x]^{\frac{1}{2}}$ untuk setiap $x \in V$ merupakan suatu norm pada $V$. 
Ruang Semi Hasil Kali Dalam pada Ruang Bernorm Kompleks 71

(b) Untuk setiap $x, y \in V$, fungsional $f_{y}: V \longrightarrow \mathbb{C}$ yang didefinisikan sebagai $f_{y}(x)=[x, y]$ merupakan suatu fungsional linear kontinu pada $V$ dan $\left\|f_{y}\right\|=$ $\|y\|$.

\subsection{Eksistensi Semi Hasilkali Dalam}

Teorema 3.4. [2] Misalkan $(V,\|\|$.$) suatu ruang bernorm kompleks. Maka setiap$ semi hasil kali dalam pada $V$ didefinisikan sebagai

$$
[x, y]=(\tilde{\jmath}(y))(x) \text { untuk setiap } x, y \in V,
$$

dimana $\tilde{\jmath}$ adalah suatu section dari normalized duality mapping $\jmath$ pada $V$.

Lema 3.5. [3] Misalkan $x=\left(x_{1}, x_{2}, x_{3}, \ldots\right), y=\left(y_{1}, y_{2}, y_{3}, \ldots\right)$ dan $z=$ $\left(z_{1}, z_{2}, z_{3}, \ldots\right)$ merupakan vektor-vektor sebarang pada ruang $l^{p}$ untuk $1 \leq p<\infty$ sedemikian hingga $\sum_{i=1}^{\infty}\left|x_{i}\right|^{p}<\infty$ untuk setiap $x_{i} \in \mathbb{C}, \sum_{i=1}^{\infty}\left|y_{i}\right|^{p}<\infty$ untuk setiap $y_{i} \in \mathbb{C}$ dan $\sum_{i=1}^{\infty}\left|z_{i}\right|^{p}<\infty$ untuk setiap $z_{i} \in \mathbb{C}$. Maka

$$
\sum_{i=1}^{\infty} x_{i}{ }^{p-2} y_{i} z_{i} \leq\left(\sum_{i=1}^{\infty}\left|x_{i}\right|^{p}\right)^{\frac{p-2}{p}}\left(\sum_{i=1}^{\infty}\left|y_{i}\right|^{p}\right)^{\frac{1}{p}}\left(\sum_{i=1}^{\infty}\left|z_{i}\right|^{p}\right)^{\frac{1}{p}} .
$$

Contoh 3.6. Misalkan $\left(l^{p},\|\cdot\|_{p}\right)$ suatu ruang bernorm kompleks dengan norm yang didefinisikan sebagai

$$
\|x\|_{p}=\left(\sum_{k=1}^{\infty}\left|x_{k}\right|^{p}\right)^{\frac{1}{p}} \text { untuk setiap } x=\left(x_{1}, x_{2}, x_{3}, \cdots\right) \in l^{p},
$$

dimana $1 \leq p<\infty, p \neq 2$. Suatu fungsi $[.,]:. l^{p} \times l^{p} \rightarrow \mathbb{C}$ didefinisikan sebagai

$$
[x, y]=\|y\|_{p}^{2-p} \sum_{k=1}^{\infty} x_{k} \overline{y_{k}}\left|y_{k}\right|^{p-2}
$$

untuk setiap $x=\left(x_{1}, x_{2}, x_{3}, \cdots\right), y=\left(y_{1}, y_{2}, y_{3}, \cdots\right) \in l^{p}$ adalah suatu semi hasil kali dalam pada $l^{p}$.

Hal ini dapat dijelaskan sebagai berikut.

(1) $[x+y, z]=\|z\|_{p}{ }^{2-p} \sum_{k=1}^{\infty}\left(x_{k}+y_{k}\right) \overline{\left(z_{k}\right)}\left|z_{k}\right|^{p-2}=\|z\|_{p}{ }^{2-p} \sum_{k=1}^{\infty} x_{k} \overline{\left(z_{k}\right)}\left|z_{k}\right|^{p-2}+$ $\|z\|_{p}^{2-p} \sum_{k=1}^{\infty} y_{k} \overline{\left(z_{k}\right)}\left|z_{k}\right|^{p-2}=[x, z]+[y, z]$.

(2)(a) $[\lambda x, y]=\|y\|_{p}^{2-p} \sum_{k=1}^{\infty}\left(\lambda x_{k}\right) \overline{\left(y_{k}\right)}\left|y_{k}\right|^{p-2}=(\lambda)\|y\|_{p}^{2-p} \sum_{k=1}^{\infty} x_{k} \overline{\left(y_{k}\right)}\left|y_{k}\right|^{p-2}=$ $\lambda[x, y]$.

(b) $[x, \lambda y]=\|\lambda y\|_{p}{ }^{2-p} \sum_{k=1}^{\infty} x_{k} \overline{\left(\lambda y_{k}\right)}\left|\lambda y_{k}\right|^{p-2}=\left(|\lambda|^{2-p}\right)(\bar{\lambda})\left(|\lambda|^{p-2}\right)$ $\left(\|y\|_{p}^{2-p} \sum_{k=1}^{\infty} x_{k} \overline{\left(y_{k}\right)}\left|y_{k}\right|^{p-2}\right)=\bar{\lambda}[x, y]$. 
(3) (a) $[x, x]=\|x\|_{p}^{2-p} \sum_{k=1}^{\infty}\left|x_{k}\right|^{2}\left|x_{k}\right|^{p-2}=\|x\|_{p}^{2-p} \sum_{k=1}^{\infty}\left|x_{k}\right|^{p}$.

Untuk $1 \leq p<\infty, p \neq 2$ dan $k=1,2,3, \cdots$, berlaku $\sum_{k=1}^{\infty}\left|x_{k}\right|^{p} \geq 0$ dan $\|x\|_{p}{ }^{2-p} \geq 0$. Diperoleh $[x, x]=\|x\|_{p}{ }^{2-p} \sum_{k=1}^{\infty}\left|x_{k}\right|^{p} \geq 0$.

(b) $[x, x]$

$$
\|x\|_{p}^{2-p} \sum_{k=1}^{\infty}\left|x_{k}\right|^{2}\left|x_{k}\right|^{p-2}
$$

$=\left(\sum_{k=1}^{\infty}\left|x_{k}\right|^{p}\right)^{\frac{2-p}{p}} \sum_{k=1}^{\infty}\left|x_{k}\right|^{p}=\left(\sum_{k=1}^{\infty}\left|x_{k}\right|^{p}\right)^{\frac{2}{p}}=0$ hanya dipenuhi jika $x=$ $\left(x_{1}, x_{2}, x_{3}, \cdots\right)=(0,0,0, \cdots)=0$.

(4)

$$
\begin{aligned}
& |[x, y]|^{2}=\left.\left.\left|\|y\|_{p}^{2-p} \sum_{k=1}^{\infty} x_{k} \overline{\left(y_{k}\right)}\right| y_{k}\right|^{p-2}\right|^{2}, \\
& =\left(\sum_{k=1}^{\infty}\left|y_{k}\right|^{p}\right)^{\frac{2-p}{p}}\left(\sum_{k=1}^{\infty} x_{k} \overline{\left(y_{k}\right)}\left|y_{k}\right|^{p-2}\right)\left(\sum_{k=1}^{\infty}\left|y_{k}\right|^{p}\right)^{\frac{2-p}{p}}\left(\sum_{k=1}^{\infty} \overline{x_{k}} y_{k}{\overline{\left|y_{k}\right|}}^{p-2}\right), \\
& =\left(\sum_{k=1}^{\infty}\left|y_{k}\right|^{p}\right)^{\frac{2(2-p)}{p}}\left(\sum_{k=1}^{\infty} x_{k} \overline{\left(y_{k}\right)}\left|y_{k}\right|^{p-2}\right)\left(\sum_{k=1}^{\infty} \overline{x_{k}} y_{k}{\overline{y_{k} \mid}}^{p-2}\right) \text {, } \\
& \leq\left(\sum_{k=1}^{\infty}\left|y_{k}\right|^{p}\right)^{\frac{2(2-p)}{p}}\left(\left[\sum_{k=1}^{\infty}\left|y_{k}\right|^{p}\right]^{\frac{p-2}{p}}\left[\sum_{k=1}^{\infty}\left|x_{k}\right|^{p}\right]^{\frac{1}{p}}\left[\sum_{k=1}^{\infty} \frac{\left.y_{k}\right|^{p}}{{ }^{\frac{1}{p}}}\right),\right. \\
& =\left(\left[\sum_{k=1}^{\infty}{\overline{\left|y_{k}\right|}}^{p}\right]^{\frac{p-2}{p}}\left[\left.\sum_{k=1}^{\infty} \overline{\mid x_{k}}\right|^{p}\right]^{\frac{1}{p}}\left[\sum_{k=1}^{\infty}\left|y_{k}\right|^{p}\right]^{\frac{1}{p}}\right) \text {, berdasarkan Lema 3.5, } \\
& =\left[\sum_{k=1}^{\infty}\left|x_{k}\right|^{p}\right]^{\frac{2-p}{p}+\frac{p}{p}}\left[\sum_{k=1}^{\infty}\left|y_{k}\right|^{p}\right]^{\frac{2-p}{p}+\frac{p}{p}} \text {, } \\
& =\left[\sum_{k=1}^{\infty}\left|x_{k}\right|^{p}\right]^{\frac{2-p}{p}} \sum_{k=1}^{\infty}\left|x_{k}\right|^{p}\left[\sum_{k=1}^{\infty}\left|y_{k}\right|^{p}\right]^{\frac{2-p}{p}} \sum_{k=1}^{\infty}\left|y_{k}\right|^{p}, \\
& =\left(\left[\sum_{k=1}^{\infty}\left|x_{k}\right|^{p}\right]^{\frac{1}{p}}\right)^{2-p} \sum_{k=1}^{\infty}\left|x_{k}\right|^{2}\left|x_{k}\right|^{p-2}\left(\left[\sum_{k=1}^{\infty}\left|y_{k}\right|^{p}\right]^{\frac{1}{p}}\right)^{2-p} \sum_{k=1}^{\infty}\left|y_{k}\right|^{2}\left|y_{k}\right|^{p-2} \text {, } \\
& =\left(\|x\|_{p}{ }^{2-p} \sum_{k=1}^{\infty}\left(x_{k}\right) \overline{\left(x_{k}\right)}\left|x_{k}\right|^{p-2}\right)\left(\|y\|_{p}^{2-p} \sum_{k=1}^{\infty}\left(y_{k}\right) \overline{\left(y_{k}\right)}\left|y_{k}\right|^{p-2}\right), \\
& =[x, x][y, y] \text {. }
\end{aligned}
$$

Lema 3.7. [4] Misalkan $\left(S,[., .]_{S}\right)$ dan $\left(T,-[., .]_{T}\right)$ adalah ruang semi hasil kali dalam. Maka fungsi $[., .]_{S+T}:(S+T) \times(S+T) \longrightarrow \mathbb{C}$ yang didefinisikan sebagai

$$
\left[s_{1}+t_{1}, s_{2}+t_{2}\right]_{S+T}:=\left[s_{1}, s_{2}\right]_{S}+\left(-\left[t_{1}, t_{2}\right]_{T}\right)
$$

\section{Bukti.}

(1) $\left[\left(s_{1}+t_{1}\right)+\left(s_{2}+t_{2}\right), s_{3}+t_{3}\right]_{S+T}=\left[\left(s_{1}+s_{2}\right)+\left(t_{1}+t_{2}\right), s_{3}+t_{3}\right]_{S+T}=$ 
$=\left[s_{1}+s_{2}, s_{3}\right]_{S}+\left(-\left[t_{1}+t_{2}, t_{3}\right]_{T}\right)=\left[s_{1}, s_{3}\right]_{S}+\left[s_{2}, s_{3}\right]_{S}+\left(-\left[t_{1}, t_{3}\right]_{T}\right)+$ $\left(-\left[t_{2}, t_{3}\right]_{T}\right)=\left[s_{1}+t_{1}, s_{3}+t_{3}\right]_{S+T}+\left[s_{2}+t_{2}, s_{3}+t_{3}\right]_{S+T}$.

(2) (a) $\left[\lambda\left(s_{1}+t_{1}\right), s_{2}+t_{2}\right]_{S+T}=\left[\lambda s_{1}, s_{2}\right]_{S}+\left(-\left[\lambda t_{1}, t_{2}\right]_{T}\right)=\lambda\left[s_{1}+t_{1}, s_{2}+t_{2}\right]_{S+T}$.

(b) $\left[s_{1}+t_{1}, \lambda\left(s_{2}+t_{2}\right)\right]_{S+T}=\left[s_{1}, \lambda s_{2}\right]_{S}+\left(-\left[t_{1}, \lambda t_{2}\right]_{T}\right)=\bar{\lambda}\left[s_{1}+t_{1}, s_{2}+t_{2}\right]_{S+T}$.

(3) (a) Jelas fungsi $[., .]_{S+T}$ nonnegatif berdasarkan definisi semi hasil kali dalam pada $S$ dan $T$.

(b) Misalkan $\left[s_{1}+t_{1}, s_{1}+t_{1}\right]_{S+T}=\left[s_{1}, s_{1}\right]_{S}+\left(-\left[t_{1}, t_{1}\right]_{T}\right)=0$. Karena $[.,,]_{S}$ dan $[., .]_{T}$ merupakan semi hasil kali dalam, maka $\left[s_{1}, s_{1}\right]_{S}+\left(-\left[t_{1}, t_{1}\right]_{T}\right)=0$ dipenuhi hanya jika $\left[s_{1}, s_{1}\right]_{S}=0$ dan $\left[t_{1}, t_{1}\right]_{T}=0 .\left[s_{1}, s_{1}\right]_{S}=0 \Rightarrow s_{1}=0$ dan $\left[t_{1}, t_{1}\right]_{T}=0 \Rightarrow t_{1}=0$. Diperoleh $s_{1}+t_{1}=0+0=0$.

(4) Perhatikan bahwa

$$
\begin{aligned}
\left.\mid\left[s_{1}+t_{1}, s_{2}+t_{2}\right)\right]\left._{S+T}\right|^{2}= & \left(\left[s_{1}, s_{2}\right]_{S}+\left(-\left[t_{1}, t_{2}\right]_{T}\right)\right)\left(\overline{\left[s_{1}, s_{2}\right]_{S}}+\left(-\left[\bar{t}_{1}, t_{2}\right]_{T}\right)\right) \\
= & {\left[s_{1}, s_{2}\right]_{S} \overline{\left[s_{1}, s_{2}\right]_{S}}+\left(-\left[t_{1}, t_{2}\right]_{T}\right)\left(-\left[t_{1}, t_{2}\right]_{T}\right)+\left[s_{1}, s_{2}\right]_{S}\left(-\left[t_{1}, t_{2}\right]_{T}\right)+} \\
& \left(-\left[t_{1}, t_{2}\right]_{T}\right) \overline{\left[s_{1}, s_{2}\right]_{S}} \\
= & \left.\left|\left[s_{1}, s_{2}\right]_{S}\right|^{2}+\left|-\left[t_{1}, t_{2}\right]_{T}\right|^{2}+\left[s_{1}, s_{2}\right]_{S}\left(-\left[t_{1}, t_{2}\right]_{T}\right)+\overline{\left(\left(-\left[t_{1}, t_{2}\right]_{T}\right) \overline{\left[s_{1}, s_{2}\right]_{S}}\right)}\right) \\
\leq & {\left[s_{1}, s_{1}\right]_{S}\left[s_{2}, s_{2}\right]_{S}+\left(-\left[t_{1}, t_{1}\right]_{T}\right)\left(-\left[t_{2}, t_{2}\right]_{T}\right)+\left[s_{1}, s_{2}\right]_{S}\left(-\left[t_{1}, t_{2}\right]_{T}\right)+} \\
& \left(\left[s_{1}, s_{2}\right]_{S}\left(-\overline{\left.\left.t_{1}, t_{2}\right]_{T}\right)}\right)\right. \\
= & {\left[s_{1}, s_{1}\right]_{S}\left[s_{2}, s_{2}\right]_{S}+\left(-\left[t_{1}, t_{1}\right]_{T}\right)\left(-\left[t_{2}, t_{2}\right]_{T}\right)+2\left|\left[s_{1}, s_{2}\right]_{S}\right|\left|\left(-\left[t_{1}, t_{2}\right]_{T}\right)\right| } \\
= & {\left[s_{1}, s_{1}\right]_{S}\left[s_{2}, s_{2}\right]_{S}+\left(-\left[t_{1}, t_{1}\right]_{T}\right)\left(-\left[t_{2}, t_{2}\right]_{T}\right)+} \\
& 2 \sqrt{\left[s_{1}, s_{1}\right]_{S}\left[s_{2}, s_{2}\right]_{S}\left(-\left[t_{1}, t_{1}\right]_{T}\right)\left(-\left[t_{2}, t_{2}\right]_{T}\right)} \\
\leq & {\left[s_{1}, s_{1}\right]_{S}\left[s_{2}, s_{2}\right]_{S}+\left(-\left[t_{1}, t_{1}\right]_{T}\right)\left(-\left[t_{2}, t_{2}\right]_{T}\right)+} \\
& {\left[s_{1}, s_{1}\right]_{S}\left(-\left[t_{2}, t_{2}\right]_{T}\right)+\left[s_{2}, s_{2}\right]_{S}\left(-\left[t_{1}, t_{1}\right]_{T}\right) } \\
= & \left(\left[s_{1}, s_{1}\right]_{S}+\left(-\left[t_{1}, t_{1}\right]_{T}\right)\right)\left(\left[s_{2}, s_{2}\right]_{S}+\left(-\left[t_{2}, t_{2}\right]_{T}\right)\right) \\
= & {\left.\left.\left[s_{1}+t_{1}, s_{1}+t_{1}\right)\right]^{-}\left[s_{2}+t_{2}, s_{2}+t_{2}\right)\right]^{-} . }
\end{aligned}
$$

Contoh 3.8. Misalkan $\left(S,[.,]_{S}\right)$ adalah suatu ruang semi hasil kali dalam dimana $S$ adalah suatu ruang bernorm kompleks $\left(l^{p_{1}},\|\cdot\|_{p_{1}}\right)$, dimana $1 \leq p_{1}<\infty$ dan $p_{1} \neq 2$ dengan semi hasil kali dalam yang didefinisikan sebagai

$$
\left[s^{\prime}, s\right]_{S}:=\|s\|_{p_{1}}^{2-p_{1}} \sum_{k=1}^{\infty} s_{k}^{\prime} \overline{s_{k}}\left|s_{k}\right|^{p_{1}-2},
$$

untuk setiap $s, s^{\prime} \in S$ dengan $\|s\|_{p_{1}}=\left(\sum_{k=1}^{\infty}\left|s_{k}\right|^{p_{1}}\right)^{\frac{1}{p_{1}}}$.

Misalkan $\left(T,[.,]_{T}\right)$ adalah suatu ruang semi hasil kali dalam dimana $T$ adalah suatu ruang bernorm kompleks $\left(l^{p_{2}},\|\cdot\|_{p_{2}}\right)$, dimana $1 \leq p_{2}<\infty$ dan $p_{2} \neq 2$ dengan 
semi hasil kali dalam yang didefinisikan sebagai

$$
\left[t^{\prime}, t\right]_{T}:=\|t\|_{p_{2}}{ }^{2-p_{2}} \sum_{k=1}^{\infty} t_{k}^{\prime} \overline{t_{k}}\left|t_{k}\right|^{p_{2}-2}
$$

untuk setiap $t, t^{\prime} \in T$ dengan $\|t\|_{p_{2}}=\left(\sum_{k=1}^{\infty}\left|t_{k}\right|^{p_{2}}\right)^{\frac{1}{p_{2}}}$.

Suatu fungsi $[., .]_{S+T}:(S+T) \times(S+T) \longrightarrow \mathbb{C}$ yang didefinisikan sebagai

$$
\left[s^{\prime}+t^{\prime}, s+t\right]_{S+T}:=\left[s^{\prime}, s\right]_{S}+\left[t^{\prime}, t\right]_{T},
$$

untuk setiap $\left(s^{\prime}+t^{\prime}\right),(s+t) \in S+T$ merupakan suatu semi hasil kali dalam pada ruang vektor kompleks $S+T$.

Hal ini dapat dijelaskan sebagai berikut.

$$
\begin{aligned}
{\left[\left(s^{\prime}+t^{\prime}\right)+\left(s^{\prime \prime}+t^{\prime \prime}\right), s+t\right]_{S+T} } & =\left[\left(s^{\prime}+s^{\prime \prime}\right)+\left(t^{\prime}+t^{\prime \prime}\right), s+t\right]_{S+T} \\
& =\left[s^{\prime}+s^{\prime \prime}, s\right]_{S}+\left[t^{\prime}+t^{\prime \prime}, t\right]_{T}
\end{aligned}
$$

Langkah penyelesaian menggunakan cara yang sama pada Contoh 3.6 bagian 1, sehingga diperoleh $\left[s^{\prime}+s^{\prime \prime}, s\right]_{S}=\left[s^{\prime}, s\right]_{S}+\left[s^{\prime \prime}, s\right]_{S}$ dan $\left[t^{\prime}+t^{\prime \prime}, t\right]_{T}=\left[t^{\prime}, t\right]_{T}+$ $\left[t^{\prime \prime}, t\right]_{T}$.

$$
\begin{aligned}
{\left[\left(s^{\prime}+t^{\prime}\right)+\left(s^{\prime \prime}+t^{\prime \prime}\right), s+t\right]_{S+T} } & =\left[s^{\prime}+s^{\prime \prime}, s\right]_{S}+\left[t^{\prime}+t^{\prime \prime}, t\right]_{T} \\
& =\left[s^{\prime}, s\right]_{S}+\left[t^{\prime}, t\right]_{T}+\left[s^{\prime \prime}, s\right]_{S}+\left[t^{\prime \prime}, t\right]_{T} \\
& =\left[s^{\prime}+t^{\prime}, s+t\right]_{S+T}+\left[s^{\prime \prime}+t^{\prime \prime}, s+t\right]_{S+T} .
\end{aligned}
$$

(2) (a) $\left[\lambda\left(s^{\prime}+t^{\prime}\right), s+t\right]_{S+T}=\left[\lambda s^{\prime}+\lambda t^{\prime}, s+t\right]_{S+T}$

$$
=\left[\lambda s^{\prime}, s\right]_{S}+\left[\lambda t^{\prime}+t\right]_{T} \text {. }
$$

Langkah penyelesaian menggunakan cara yang sama pada Contoh 3.6 bagian 2(a), sehingga diperoleh $\left[\lambda s^{\prime}, s\right]_{S}=\lambda\left[s^{\prime}, s\right]_{S}$ dan $\left[\lambda t^{\prime}, t\right]_{T}=\lambda\left[t^{\prime}, t\right]_{T}$.

$$
\begin{aligned}
{\left[\lambda\left(s^{\prime}+t^{\prime}\right), s+t\right]_{S+T} } & =\left[\lambda s^{\prime}, s\right]_{S}+\left[\lambda t^{\prime}+t\right]_{T} \\
& =\lambda\left(\left[s^{\prime}, s\right]_{S}+\left[t^{\prime}, t\right]_{T}\right) \\
& =\lambda\left[s^{\prime}+t^{\prime}, s+t\right]_{S+T} . \\
\text { (b) }\left[s^{\prime}+t^{\prime}, \lambda(s+t)\right]_{S+T} & =\left[s^{\prime}+t^{\prime}, \lambda s+\lambda t\right]_{S+T} \\
& =\left[s^{\prime}, \lambda s\right]_{S}+\left[t^{\prime}, \lambda t\right]_{T} .
\end{aligned}
$$

Langkah penyelesaian menggunakan cara yang sama pada Contoh 3.6 bagian 2(b), sehingga diperoleh $\left[s^{\prime}, \lambda s\right]_{S}=\bar{\lambda}\left[s^{\prime}, s\right]_{S}$ dan $\left[t^{\prime}, \lambda t\right]_{T}=\bar{\lambda}\left[t^{\prime}, t\right]_{T}$.

$$
\begin{aligned}
{\left[s^{\prime}+t^{\prime}, \lambda(s+t)\right]_{S+T} } & =\left[s^{\prime}, \lambda s\right]_{S}+\left[t^{\prime}, \lambda t\right]_{T} \\
& =\bar{\lambda}\left(\left[s^{\prime}, s\right]_{S}+\left[t^{\prime}+t\right]_{T}\right) \\
& =\bar{\lambda}\left[s^{\prime}+t^{\prime}, s+t\right]_{S+T} .
\end{aligned}
$$

(3) (a) $[s+t, s+t]_{S+T}=[s, s]_{S}+[t, t]_{T}$. Langkah penyelesaian menggunakan cara yang sama pada Contoh 3.6 bagian $3(\mathrm{a})$, sehingga diperoleh $[s, s]_{S} \geq 0$ dan $[t, t]_{T} \geq 0$. Karena $[s, s]_{S} \geq 0$ dan $[t, t]_{T} \geq 0$, maka $[s+t, s+t]_{S+T}=$ $[s, s]_{S}+[t, t]_{T} \geq 0$.

(b) $[s+t, s+t]_{S+T}=[s, s]_{S}+[t, t]_{T}$. Langkah penyelesaian menggunakan cara yang sama pada Contoh 3.6 bagian $3(\mathrm{~b})$, sehingga diperoleh $[s, s]_{S}=$ $\left(\sum_{k=1}^{\infty}\left|s_{k}\right|^{p_{1}}\right)^{\frac{2}{p_{1}}} \operatorname{dan}[t, t]_{T}=\left(\sum_{k=1}^{\infty}\left|t_{k}\right|^{p_{2}}\right)^{\frac{2}{p_{2}}}$. 
Ruang Semi Hasil Kali Dalam pada Ruang Bernorm Kompleks 75

$$
\begin{aligned}
& {[s+t, s+t]_{S+T}=\left(\sum_{k=1}^{\infty}\left|s_{k}\right|^{p_{1}}\right)^{\frac{2}{p_{1}}}+\left(\sum_{k=1}^{\infty}\left|t_{k}\right|^{p_{2}}\right)^{\frac{2}{p_{2}}}=0 \text { hanya dipenuhi jika }} \\
& s=\left(s_{1}, s_{2}, s_{3}, \cdots\right)=(0,0,0, \cdots)=0 \text { dan } t=\left(t_{1}, t_{2}, t_{3}, \cdots\right)=(0,0,0, \cdots)=0 . \\
& \text { Diperoleh } s+t=\left(s_{1}+t_{1}, s_{2}+t_{2}, s_{3}+t_{3}, \cdots\right)=(0+0,0+0,0+0, \cdots)=0 .
\end{aligned}
$$

(4)

$$
\left|\left[s^{\prime}+t^{\prime}, s+t\right]_{S+T}\right|^{2}=\left.\left|\|s\|_{p_{1}}{ }^{2-p_{1}} \sum_{k=1}^{\infty} s_{k}^{\prime} \overline{\left(s_{k}\right)}\right| s_{k}\right|^{p_{1}-2}+\left.\|t\|_{p_{2}}{ }^{2-p_{2}} \sum_{k=1}^{\infty} t_{k}^{\prime} \overline{\left(t_{k}\right)}\left|t_{k}\right|^{p_{2}-2}\right|^{2} .
$$

Misalkan

$$
\begin{aligned}
& x=\|s\|_{p_{1}}{ }^{2-p_{1}} \sum_{k=1}^{\infty} s_{k}^{\prime} \overline{\left(s_{k}\right)}\left|s_{k}\right|^{p_{1}-2}, \\
& y=\|t\|_{p_{2}}{ }^{2-p_{2}} \sum_{k=1}^{\infty} t_{k}^{\prime} \overline{\left(t_{k}\right)}\left|t_{k}\right|^{p_{2}-2} .
\end{aligned}
$$

Perhatikan bahwa

$$
\left|\left[s^{\prime}+t^{\prime}, s+t\right]_{S+T}\right|^{2}=|x+y|^{2}=x \bar{x}+y \bar{y}+x \bar{y}+y \bar{x},
$$

dengan

$$
\begin{aligned}
& x \bar{x} \leq\left[\sum_{k=1}^{\infty}\left|s_{k}^{\prime}\right|^{p_{1}}\right]^{\frac{2}{p_{1}}}\left[\sum_{k=1}^{\infty}\left|s_{k}\right|^{p_{1}}\right]^{\frac{2}{p_{1}}}, \\
& y \bar{y} \leq\left[\sum_{k=1}^{\infty}\left|t_{k}^{\prime}\right|^{p_{2}}\right]^{\frac{2}{p_{2}}}\left[\sum_{k=1}^{\infty}\left|t_{k}\right|^{p_{2}}\right]^{\frac{2}{p_{2}}}, \\
& x \bar{y} \leq\left(\left[\sum_{k=1}^{\infty}\left|t_{k}^{\prime}\right|^{p_{2}}\right]^{\frac{1}{p_{2}}}\left[\sum_{k=1}^{\infty}\left|t_{k}\right|^{p_{2}}\right]^{\frac{1}{p_{2}}}\right)\left(\left[\sum_{k=1}^{\infty}\left|s_{k}^{\prime}\right|^{p_{1}}\right]^{\frac{1}{p_{1}}}\left[\sum_{k=1}^{\infty}\left|s_{k}\right|^{p_{1}}\right]^{\frac{1}{p_{1}}}\right), \\
& y \bar{x} \leq\left(\left[\sum_{k=1}^{\infty}\left|t_{k}^{\prime}\right|^{p_{2}}\right]^{\frac{1}{p_{2}}}\left[\sum_{k=1}^{\infty}\left|t_{k}\right|^{p_{2}}\right]^{\frac{1}{p_{2}}}\right)\left(\left[\sum_{k=1}^{\infty}\left|s_{k}^{\prime}\right|^{p_{1}}\right]^{\frac{1}{p_{1}}}\left[\sum_{k=1}^{\infty}\left|s_{k}\right|^{p_{1}}\right]^{\frac{1}{p_{1}}}\right) .
\end{aligned}
$$

Perhatikan bahwa

$$
\begin{aligned}
\left|\left[s^{\prime}+t^{\prime}, s+t\right]_{S+T}\right|^{2} \leq & {\left[\sum_{k=1}^{\infty}\left|s_{k}^{\prime}\right|^{p_{1}}\right]^{\frac{2}{p_{1}}}\left[\sum_{k=1}^{\infty}\left|s_{k}\right|^{p_{1}}\right]^{\frac{2}{p_{1}}}+\left[\sum_{k=1}^{\infty}\left|t_{k}^{\prime}\right|^{p_{2}}\right]^{\frac{2}{p_{2}}}\left[\sum_{k=1}^{\infty}\left|t_{k}\right|^{p_{2}}\right]^{\frac{2}{p_{2}}}+} \\
& 2\left(\left[\sum_{k=1}^{\infty}\left|t_{k}^{\prime}\right|^{p_{2}}\right]^{\frac{1}{p_{2}}}\left[\sum_{k=1}^{\infty}\left|t_{k}\right|^{p_{2}}\right]^{\frac{1}{p_{2}}}\right)\left(\left[\sum_{k=1}^{\infty}\left|s_{k}^{\prime}\right|^{p_{1}}\right]^{\frac{1}{p_{1}}}\left[\sum_{k=1}^{\infty}\left|s_{k}\right|^{p_{1}}\right]^{\frac{1}{p}}\right) .
\end{aligned}
$$

Misalkan

$$
\begin{aligned}
& A=\left[\sum_{k=1}^{\infty}\left|s_{k}^{\prime}\right|^{p_{1}}\right]^{\frac{1}{p_{1}}}, B=\left[\sum_{k=1}^{\infty}\left|s_{k}\right|^{p_{1}}\right]^{\frac{1}{p_{1}}}, \\
& C=\left[\sum_{k=1}^{\infty}\left|t_{k}^{\prime}\right|^{p_{2}}\right]^{\frac{1}{p_{2}}}, D=\left[\sum_{k=1}^{\infty}\left|t_{k}\right|^{p_{2}}\right]^{\frac{1}{p_{2}}} .
\end{aligned}
$$


Maka diperoleh

$$
\left|\left[s^{\prime}+t^{\prime}, s+t\right]_{S+T}\right|^{2} \leq A^{2} B^{2}+C^{2} D^{2}+2 C D A B .
$$

Karena $2 C D A B=A^{2} D^{2}+B^{2} C^{2}-(A D-B C)^{2}$, maka

$$
\begin{aligned}
\left|\left[s^{\prime}+t^{\prime}, s+t\right]_{S+T}\right|^{2} & \leq A^{2} B^{2}+C^{2} D^{2}+2 C D A B, \\
& =A^{2} B^{2}+C^{2} D^{2}+A^{2} D^{2}+B^{2} C^{2}-(A D-B C)^{2}, \\
& \leq A^{2} B^{2}+C^{2} D^{2}+A^{2} D^{2}+B^{2} C^{2}, \\
& =A^{2} B^{2}+A^{2} D^{2}+B^{2} C^{2}+C^{2} D^{2}, \\
& =\left(A^{2}+C^{2}\right)\left(B^{2}+D^{2}\right), \\
& =\left(\left[\sum_{k=1}^{\infty}\left|s_{k}^{\prime}\right|^{p_{1}}\right]^{\frac{2}{p_{1}}}+\left[\sum_{k=1}^{\infty}\left|t_{k}^{\prime}\right|^{p_{2}}\right]^{\frac{2}{p_{2}}}\right)\left(\left[\sum_{k=1}^{\infty}\left|s_{k}\right|^{p_{1}}\right]^{\frac{2}{p_{1}}}+\left[\sum_{k=1}^{\infty}\left|t_{k}\right|^{p_{2}}\right]^{\frac{2}{p_{2}}}\right), \\
& =\left[s^{\prime}+t^{\prime}, s^{\prime}+t^{\prime}\right]_{S+T}[s+t, s+t]_{S+T} .
\end{aligned}
$$

\section{Kesimpulan}

Suatu ruang bernorm kompleks dapat dibentuk menjadi ruang semi hasil kali dalam menggunakan hubungan antara normalized duality mapping pada ruang bernorm kompleks dengan semi hasil kali dalam. Suatu ruang semi hasil kali dalam merupakan suatu ruang bernorm kompleks dengan norm yang dibangun oleh semi hasil kali dalam.

\section{Ucapan Terima Kasih}

Ucapan terima kasih disampaikan kepada Monika Rianti Helmi, M.Si, Dr. Yanita, Dr. Jenizon, yang telah memberi masukan dan saran sehingga penelitian ini dapat terselesaikan.

\section{Daftar Pustaka}

[1] Debnath, L. dan Mikusinski, P. 2003. Introduction to Hilbert Space with Application. Academic Press, San Diego

[2] Dragomir, S. S. 1991. Semi Inner Product and Applications. School of Computer Science and Mathematics Victoria University of Technology, Melbourne

[3] Idris, M. dan Gunawan, H. 2015. p-summable sequence space with inner product. Beu J. Sci. Techn. 5: $37-41$

[4] Horváth, G. Á. 2009. Semi-indefinite-inner-product and Generalized Minkowski Spaces. Journal of Geometry and Physics. 60 : $1190-1208$

[5] Kreyzig, E. 1978. Introduction Functional Analysis with Application. Wiley Classics Library, New York

[6] Lumer, G. 1961. Semi Inner Product Spaces. Trans. Amer. Math. Soc. 100: $29-43$

[7] Maddox, J. I. Elements of Functional Analysis. The Syndics of the Cambridge University Press, Cambridge

[8] Rynne, B. P. dan Youngson, M. A. 2008. Linier Functional Analysis. SpringerVerlaq, New York 